\title{
Practicing what we preach
}

\author{
M. Lawton \\ Landcare Research, New Zealand
}

\begin{abstract}
In 2001 Landcare Research embarked on a journey into the unknown - the design and development of premises for 100 of our staff in Auckland. Sustainability is the central thread of Landcare Research's core business but we also try to practise what we preach, so when we came to build new accommodation, we knew we had to be innovative and to some extent courageous in breaking new ground. We set and achieved high environmental and sustainable design objectives for the building, based on our ethos as an organisation that champions sustainable development through lowering resource use and dramatically reducing waste. We agreed that the building had to be designed for sustainability. Construction costs were not to be increased because the building was sustainable. Projected energy operating costs should be about $60-70 \%$ less than for a conventional building. The building would make minimal use of municipal water, stormwater and sewage systems. In addition, we wanted the building to be a great place to work and to reflect our Pacific culture and specific Auckland location. We continue to adhere to those principles in our ongoing management of the building, and monitor and manage it as a research and demonstration site for low-impact urban design.

This presentation will outline the drivers of sustainability in New Zealand and how they were translated into the goals we set ourselves for our sustainable building. It will also focus on the problems that face design professionals and their clients when they choose developments that are not mainstream, and present suggestions to overcome them.
\end{abstract}

Keywords: sustainable architecture, energy efficiency, water management.

\section{Introduction}

It is now well accepted that the world has a limited source of natural resources and a limited ability to deal with waste. That's a given, a fundamental law of 
nature. Our global footprint, the amount of resource used globally, already exceeds by a third a level that can be defined as sustainable, that is will allow for the needs of future generations [1]. In addition, the footprint varies widely between countries emphasising global inequities. In New Zealand we have not yet exceeded our footprint but that is only because we have a magnificent landscape and small population. It is possible that previous post-industrial generations could be forgiven such extravagance; they simply did not have the data, even if they may have sensed that all was not well. The present occupants of this planet do not have that excuse. Despite the fact that science has still much to learn about how the world works, how species evolve, how climate cycles are influenced and what feedback mechanisms exist, the pattern of Western living will need to be changed, sooner or later, to adjust to global environmental concerns. The increasing development of China and India will only accelerate a global environmental crisis already on the horizon.

So that is the big picture, a huge political, technical, social and economic web to disentangle so that we can find the balance that allows for global societal wellbeing in a sustainable way. All countries will face the same pressures, some more than others, but New Zealand with all its inherent natural wealth should be leading the way, a natural design laboratory for the world.

What are the key urban development issues in New Zealand? The main consideration has been the provision of future energy sources, but the need to upgrade stormwater and sewage disposal systems is also of concern.

Discussion usually seems to focus on the need to replace and rebuild, to find new sources, and to ensure above all else that we maintain our current high standard of living. Implicit in that way of thinking is that our behaviour need not be required to change, that we should be able to keep on using power whenever we want and should not have to think about how we get rid of any waste other then a modest attempt to recycle our newspapers, wine bottles and some plastic domestic solid waste. We know we could be less resource consumptive and produce less waste but that requires a change in behaviour, not an impossible task but something that could be facilitated by good leadership and a political and economic framework that encourages sustainable development. It is easy to say that people are the problem but behaviour would be strongly influenced by a more innovative approach from town planners, architects, engineers, local body politicians and industry. Much easier to be "green" in a house that does not need much energy or in a society that does not buy produce in excess wrapping or that lives in houses with toilet waste systems that do not require large amounts of water to flush away the contents.

In the case of energy, a substantial reduction in energy demand, along with the development of a wider range of renewable energy sources, would diminish New Zealand's issue of looming power failures and the need to enhance energy generation from fossil fuels. We should maintain a national grid by all means, but have that grid supplemented by local grids supplied through individual buildings that contribute or draw from the system as required. Let the grid act as a battery but have as much energy as possible generated where it will be used. Then design houses and develop precincts that minimise the need for energy 
through orientation, aspect and material selection, and New Zealand, with its modest population growth predictions, would have no trouble in achieving its power needs without compromising productivity and comfort.

Stormwater is a major problem wherever there are modest to major communities. The problem is two fold: the disruption of the hydrologic cycle by concentrating stormwater in pipes, leading to flash floods; and the contaminants, carried by the stormwater, mainly from road transport, which end up in our streams and harbours. Impervious surfaces add to both problems. The percentage of many urban impervious surfaces has increased in the last few years through in-fill housing, much smaller sections and larger houses and large tar-sealed driveways. No wonder the Auckland stormwater system is in trouble. There is insufficient natural filtration of water through the soil both to moderate its flow and absorb contaminants.

Toilets, not a subject that most people want to spend time thinking about, certainly not discuss at dinner parties, are unpleasant but necessary evils, which help take our waste away so that we do not have to think about it. Their design has improved in latter years so that they have low water-use alternatives. In general, however, the principle has not changed and most still use large amounts of water directly from the municipal supply. The logic of cleaning water to potable standards and then flushing it down the toilet evades me.

With massive redevelopment projects in Auckland getting underway, there is huge potential for further environmental degradation. However, if low-impact urban design and development practices become mainstream, enormous environmental improvements could be expected - with social and economic benefits ensuing.

In any building, whether small domestic to large commercial, there are numerous improvements that could be made to limit resource use and waste production. The problem is that very few people are taking that opportunity despite the obvious advantages. Our experience in low-impact urban design in our recent building project has uncovered a number of reasons for this:

- The prospective owners do not understand the problem or what can be achieved.

- There are too few professionals in the design industry with a background in ecological engineering and sustainable architecture.

- Anything can be built if the price is right, so there is a perception and sometimes a reality that eco-buildings are more expensive than conventional buildings.

- While the design industry has some understanding of the problem, the construction industry, construction contractors and material suppliers have very little.In general developers have not been interested in moderating development to address environmental concerns. There are some exceptions.

- Building code and compliance standards can work against innovation. Often people work to the minimum standards, when going above them would be beneficial. 
- $\quad$ Risk is a major factor in that anything new may be risky and may not be suggested by the design team or the construction company, because of liability issues.

- Environmental, economic and social data need to be put in a form that is able to influence plans, codes and practice.

\section{The Landcare Research building}

Despite the above constraints and in part in blissful ignorance of the potential pitfalls, Landcare Research when it came to consider a new building for staff in Auckland, decided they wanted as sustainable building, at the forefront of ecodesign in New Zealand. Clearly they wanted a sound functional building, suitable for all the various activities staff carry out. They wanted a good place to work and agreed with the University of Auckland to co-locate onto the Tamaki Campus to facilitate collaborations with University staff. The main functions of the building provided a challenge being:

- House our national insect collections of 6.5 million insects, one million of them mounted with pins, in a state-of-the-art collection facility.

- Likewise for our national fungal collection of 600000 specimens.

- Provide for containment facilities within our laboratories to meet PC2 standards.

- $\quad$ Provide containment and propagation glasshouses.

- Ensure the building could be monitored as part of our ongoing urban research.

- Provide space for 60 Landcare Research staff, 25 MAF staff, and a number of University collaborators.

As an organisation we also had some key goals relating to sustainability:

- The building had to be designed for sustainability.

- Construction costs were not to be increased because the building was sustainable.

- Projected energy operating costs should be about $60-70 \%$ less than for a conventional building.

- $\quad$ The building would make minimal use of municipal water, stormwater and sewage systems.

We assembled a design team with some experience in sustainable buildings and were fortunate to be able to include Robert Vale from the University of Auckland to assist.

We went through many of the usual processes of seeking staff consultation through workshops and scoping our requirements. We had some of our own ideas of what a sustainable building should incorporate and we threw them into the mix.

The design and build process took 18 months and no doubt there would have been some improvements if there had been more time to explore a wide range of options. We moved into the building at Easter and have been settling in for the last 2 months. 


\subsection{Building features}

Pressure did come on the cost-plan, and the original size of the building was scaled back. Nevertheless, we are very pleased with what we have achieved through the ideas of the architects, Chow-Hill, the innovations of Connell Mott MacDonald, the forbearance of Hawkins Construction, and our own perseverance in the face of some adversity. The key features that have added to the sustainability aspects of the building are dealt with below.

\subsubsection{Energy}

The goal was to maximise passive climate control in keeping the warmth in but excess heat or cold out so that pleasant working conditions were maintained throughout the buildings irrespective of the weather outside. Inside temperatures are expected to range from 17 to $25^{\circ} \mathrm{C}$ for offices and laboratories (winter/summer) when external temperatures will be between 6 and $27^{\circ} \mathrm{C}$. We deliberately did not aim for a smaller temperature range that would have required more active climate control and intervention.

The energy consumption target is $100 \mathrm{~kW} \mathrm{hrs} / \mathrm{m}^{2} / \mathrm{yr}$ averaged over offices, collection spaces and laboratories, the latter being notoriously energy intensive. A conventional office building would consume approximately $200 \mathrm{~kW} \mathrm{hrs} / \mathrm{m}^{2} / \mathrm{yr}$, and a building with laboratories would use closer to $300 \mathrm{kw} \mathrm{hrs} / \mathrm{m}^{2} / \mathrm{yr}$. Limiting energy consumption will be achieved through design features that reduce the need for heating and cooling (minimising direct energy consumption), and by recovering and reusing waste heat. In addition to our environmental saving, good energy management will save us up to $\$ 70000$ a year. Some of the design features to help achieve that include:

2.1.1.1 Building materials The external shell of the building is multi-layered to limit heat gains from or losses to the outside. The innermost layer is a concrete block wall (keeping the thermal mass on the inside), then a thick layer of rigid fibreglass insulation, a ventilated cavity, a vapour seal layer, and finally timber or metal cladding on the outside.

Internally, exposed concrete has been used extensively to increase the thermal storage capacity of the building. During the initial decision-making design stages, innovative energy modelling software was used to optimise placement of windows and window shades and the building fabric options. The software assessed natural lighting, heating and ventilation for various times of the day, every day of the year.

2.1.1.2 Insulated walls and roof Expenditure and performance has been focussed on areas where it is needed most:

- High-performance insulation has been used for the roof, walls and floors of the Biological Collections

- Mid-level insulation (R4 fibreglass batts, which is several times the recommended amount) has been used in the atrium and office façades. 
- Low-level insulation has been used internally between air-conditioned and non-air-conditioned areas.

(A typical office loses $28-30 \mathrm{~W}$ of heat per $\mathrm{m}^{2}$ of un-insulated wall. With insulated walls this drops to $8 \mathrm{~W}$.)

2.1.1.3 Windows Windows are double-glazed, with opening frames for fresh air. Windows will need to be closed at night and during temperature extremes to help maintain the reasonably constant inside temperatures. (A typical office loses $100 \mathrm{~W}$ of heat per $1 \mathrm{~m}^{2}$ window. With double-glazing, this drops to $56 \mathrm{~W}$.)

2.1.1.4 Heat recovery ECO-AIR units that incorporate heat exchangers recover waste from the refrigerator/freezer systems, the air-conditioning/dehumidifying systems, and some of the fume cupboards. The building has 11 fume cupboards, and the energy associated with their operation (including replacing the air they suck out) is the greatest single energy use for the whole building. The refrigeration system serving the freezers and Collections space dehumidification system both contribute to a skirting radiator system throughout the offices. A gas-fired booster system has been installed to supplement, if needed, the recovered heat and solar heating systems.

2.1.1.5 Solar panels Two solar panels on the roof provide the energy needed for the hot water usage throughout the laboratory systems. The cafeteria has a separate solar hot water storage system that is independent of the laboratory systems.

2.1.1.6 Wind-powered generator A small $(400 \mathrm{~W})$ wind-powered generator by the glasshouses provides sufficient power to pump rainwater from the storage tanks (by the glasshouses) back up to the roof tanks that supply water for flushing urinals and ground floor toilets. Wind is a 'sustainable' form of energy, and incorporating a windmill generator contributes to the overall sustainability of the stormwater management on site and further reduces energy consumption from the national grid.

\subsubsection{Sewage}

The goal was to minimise the load that 90 staff, visitors and laboratory usage places on the sewer and wastewater system. The key to achieving this goal was using low-impact alternatives that meet all health and waste discharge requirements.

2.1.2.1 Composting toilets Using waste materials as a resource is a fundamental of nature or ecological systems. Human waste, once composted, is a rich source of carbon and nitrogen that can be added to soil to enrich its productive and filtering capacity.

Composting toilets are frequently considered for use in rural areas as an alternative to septic tanks. There is no reason, however, why they cannot be 
considered in a built-up area. There may be some occasions when they are simply not practical but there will be many times when they are. Putting composting toilets in our urban commercial building has been one of the more controversial aspects of the building and, it must be admitted, this feature still has its sceptics amongst the building occupants.

The first and second floors in our building have composting toilets with seven toilets feeding two large Clivus Multrum units. These toilets are located against the North wall to help keep the composting tanks warm for optimal functioning. Cleaning requires bio-friendly products similar to those used with a septic tank system. It is expected the tanks will need emptying about once every 6 months, and the tank area has external access to make servicing easier.

The system conforms to the Australian standard for composting toilets, and the New Zealand standard for on-site wastewater disposal. This means compost can go onto the surrounding gardens.

Liquid toilet waste drains to the sewer system, as do the urinals and washbasin wastewater. Wastewater from laboratories goes via local sediment/dilution traps to the sewer via a 1000-litre detention/dilution tank, and then into the sewer system. There is insufficient land area available for soakage pits for 'grey water' disposal.

2.1.2.2 Ground-floor conventional toilets For the ground floor, low water-use flush toilets have been installed. Rainwater (collected and stored on site) is used for flushing these toilets plus the urinals on all floors.

Composting toilets were not suitable for the ground floor because the hole that would have needed to be excavated for the collection unit of the composting toilets would have been below flood level. This, plus the additional costs associated with excavation, extra pumping, tanking and ventilation, made ground-floor composting toilets impracticable and uneconomic.

Overall, we have achieved our goal by ensuring that the load being placed on the sewer system is markedly smaller than for a conventional building of similar size and function.

\subsubsection{Water and wastewater management}

The goal was to reduce both the amount of water purchased from Auckland Metro and the amount of water entering the stormwater system. By harvesting rainwater and using it on site, we are reducing the need for mains water and the infrastructure needed to supply it and remove stormwater.

2.1.3.1 Rainwater harvesting Instead of rainwater running into the stormwater system, as much as possible is collected and stored on site for use in all urinals (manual flushing), ground floor toilets, and for irrigating gardens and glasshouses. Rainwater harvesting for water reuse is an obvious way of limiting the demand on future water supplies but currently it is only applied in rural areas. It is one relatively simple change that could be made to a significant percentage of our urban infrastructure. 
Water running off all the roofing areas is gravity fed to a 25000 -litre tank near the glasshouses. Water is pumped from the main storage tank back up to the roof header tank using electricity supplied by a small wind turbine.

Two additional 25 000-litre tanks detain stormwater overflow from the main tank. Overflow from the detention system (e.g., during a big storm when the tanks are already mostly full) will overflow into the rain garden (still to be constructed). A soak pit, which penetrates the basalt rock layer, allows approx $101 / \mathrm{sec}$ to drain way. Any excess over this will still enter the municipal stormwater system through the normal curbing channels and drains but the volumes will be drastically reduced compared with situations where collection and detention systems are lacking.

The cost of the tanks and wind turbine generator was offset by not needing to run downpipes to the ground and connect them to underground stormwater systems, and by savings in Auckland's Metro water charges.

Mains water is used for basins and for drinking. Although hand basins use mains water they have low-volume water-saving taps to prevent unnecessary wastage of water, including the hot water heated by solar panels.

2.1.3.2 Purified water for laboratories Reverse osmosis or hyper-filtration is the finest filtration known, and is used to provide pure water to the laboratories with specialist requirements for slide preparation and uncontaminated glassware. A reverse osmosis machine is a large consumer of water as only a small proportion of the water (maximum 30\%) flowing through the machine actually passes through the filter. The system has been configured so that the reject water can be collected for re-use in urinals and for garden irrigation, i.e. the reject water is incorporated in our stormwater management system. We have the option of using either rainwater off the roof or mains water in the reverse osmosis machine. However, using recovered rainwater may extend the life of the reverse osmosis resin filter because the rainwater probably has less dissolved salts than tap water.

2.1.3.3 Runoff from the car park and roads The car park has been constructed with a pervious gravel surface that allows rainwater to infiltrate the surface. During storms, excess water beyond what the soil can normally retain, will flow through the soil down the gentle gradient to an area to be shortly developed as a rain garden. This involves collection into a stormwater pipe to take the water under the building foyer to the front of the building where it will be released into soil and a wetland area. Any excess water will flow through the soil into the stormwater network. The overall water volume will have been significantly reduced and contaminants filtered out.

\subsubsection{Other features}

As limiting resource use was a key goal, we limited the inclusion of excess materials where possible. There are many areas with no false ceiling but exposed ceiling trays carrying pipes and wiring below the concrete upper floors or roof. Most of the office and corridor floors are concrete, which acts as a heat sink. 
Carpets used in meeting rooms and admin offices are tiles from Interface Carpets. They are off-cuts that form an interesting pattern. Once they are ready to be replaced they will be extensively recycled. Laboratory coverings are a product called Marmoleum. It looks like vinyl but is made from jute and natural resins and can be composted after its 25 -year lifetime. Organic solvents in paints and varnishes were minimised. Light fittings are low energy usage.

\section{Where to from here?}

The building has already fulfilled its purpose in a number of ways but the hope is that it will continue to be an example of some or all of the features others may wish to consider when they come to build.

We will incorporate the monitoring and management of the building into our mainstream urban research, continue to make public its performance, and suggest further improvements.

Some of the deterrents for the widespread uptake of ecological features were mentioned earlier. These are not insignificant. Some of the things to consider when going down the sustainable building path must include:

- Having a design team that is really committed to the goal and has in it some experience in sustainable design.

- Remembering that sustainable design does not have to stand out like a sore thumb, especially if that adds to the costs.

- Client and design team being prepared at this stage to take some, at least perceived, risk, in moving away from the status quo.

- Having end-users who are prepared to accept a building they may need to manage actively, to open and close windows, and to adopt a wider climate comfort range than normal.

- Choosing a framework for decision making - there are several available - and spending the time required to consider the trade-offs in terms of sustainable features, e.g., the various aspects of embodied energy in choosing materials in relation to the life-cycle of the building.

In the longer term there needs to be more fundamental changes to the Construction Industry:

- Major suppliers of materials should be aiming to procure only certified sustainable products. There needs to be better traceability so that customers know where the materials come from.

- More robust and accepted financial systems should take account of the reduced operating costs of a sustainable building and, as is often the case, the longer building lifetime when considering depreciation.

- There will either need to be a move away from working to the minimal building code and compliance standards, or those standards will need to change to encourage more sustainable behaviour.

- We had anticipated more concern from our local Council than we encountered. We were pleasantly surprised. However, for sustainable development and design to become mainstream councils need actively 
to promote such an approach through a range of mechanisms, and they also need to coordinate between their planning and consent departments to give a consistent message.

There was more time and effort involved in achieving our building than we had anticipated/planned for but it was a rewarding process, well worth the effort. We hope it can encourage others and, through some of the learning involved, make it easier for them to follow suit.

\section{Reference}

[1] Loh, J., Living Planet Report 2002, Gland Switzerland: WWW-World Fund for Nature. 